\title{
Practical technical solution for clay- contaminated sands used in concrete
}

\author{
Pierre Estephane ${ }^{1, *}$, and Klaus-Alexander Rieder ${ }^{2}$ \\ ${ }^{1}$ GCP Applied Technologies, 5006, Dubai, United Arab Emirates \\ ${ }^{2}$ GCP Applied Technologies, Cambridge, Massachusetts 02140 USA
}

\begin{abstract}
Sand, whether natural or manufactured, shows in many instances varying degrees of high levels of clay contamination. This fact is encountered in different parts of the globe and can lead to serious problems in adjusting concrete mix proportions and requiring high water to cement ratios and/or high dosages of superplasticizers without necessarily meeting the workability requirements, even when the sand is previously washed with fresh water. In this paper, different types of sand from the Gulf Cooperation Council (GCC) region are being screened, analysed for their clay contents and consequent effects on plastic concrete quality. A technical solution is being proposed based on engineered superplasticizers. A testing protocol has been established to verify the robustness of optimized mix designs demonstrating the performance of the admixture in terms of initial and extended workability. In particular, it will be demonstrated that the customized concrete admixtures constitute by themselves a stand-alone answer to the usage of clay-contaminated sands in concrete.
\end{abstract}

\section{Introduction}

Without doubt, cementing mixtures and concrete existence is prominent and very important in human civilization, historically and especially throughout the last centuries. Moreover, materials scientists and engineers understand well the value of the usage of superplasticizers in modern concrete, specifically in highly performing concrete or for particular purposes. Some of these additives attribute special characteristics to concrete from initial fluidity, to workability retention and not ending by reduced viscosity, by changing the interfacing properties of the system cement-water [2].

The concrete additives, or more precisely dispersants, of the type Polycarboxylate Ethers (PCE) are the topic of our current discussion and study. These PCEs are the latest cutting-edge technology introduced in both ready-mix and precast industries [3, 14]. Their structure is mainly carboxylic groups and non-ionic side chains of polyethers covalently attached to a polymeric anionic backbone [15]. These side chains supplement the normal dispersion with a spatial or steric repulsion $[2,15,16]$ that improves and leverages the performance of PCEs and widen their scope of usage when compared to other dispersants.

\footnotetext{
* Corresponding author: pierre.estephane@gcpat.com
} 
PCEs are already widely used all over the world in the construction industry, in different types of products ranging from low to extremely high dispersing capabilities. PCEs are well known for their high quality, extended workability retention, low dosages required and not to finish with early and uniform cement hydration. But as it is naturally with almost all manufactured products, they are not impeccable, they have weaknesses and there is always an opportunity for further development. One of the main challenges in using PCEs in concrete is the clay contained in aggregates and more often in fine aggregates. Depending on the type and amount of clay, the dispersing action of PCEs is adversely affected to different magnitudes [5].

The layered mineralogical structure of clay and the tendency of PCEs' side chains to intercalate between these layers, influence the availability and effectiveness of PCEs in dispersing cement grains $[2,3,17]$. This interaction might be seen with clay impurities in aggregates and limestone [9]. These remarkable facts give cause for concern and necessitate finding a solution applicable on an industrial scale in many parts of the world, where geologic clay deposits are mainly observed.

Many regions are of interest for the current study, and the Arabian Gulf region is leading. In Qatar, clay minerals were spotted in both fluvial and aeolian sediments with straight assumptions on their presence at various zone depths [1]. In Kuwait Bay, feldspars presence was recorded in suspended sediments up to $30 \%$ of total minerals [18], as well as the abundance of clay minerals amongst other minerals in different parts of the Bay, especially the south-eastern part [11]. The coastal plain deposits in central Kuwait were found to be medium-sized sand containing clay minerals, which are having a mineralogy dominated by illite, palygorskite, mixed layer illite-montmorillonite with minor amounts of chlorite and Kaolinite [12, 22]. The environmental impact assessment in Kuwait highlights the high daily volumes of fresh water required in quarries in the process of washing out undesirable minerals, besides the wastes disposal complications accompanying the elimination of flocculated matters [13].

All above being said and then added to the scarcity of many essential raw materials in the construction industry, the complex and sometimes multi-phased washing process of the natural or manufactured sands, with all implicated transportation costs and processing costs, made it imperative to start the pursuit for a solution $[1,13]$. A sustainable solution that reduces the complexity of screening out minerals and useful fine particles, helps in managing efficiently available sand reservoirs and untightens the strict specifications around fines in aggregates.

One answer to these problems is a new technology based on a specially engineered type of superplasticizer and used as a stand-alone product with clay-contaminated sand. This technical solution will be assessed and compared, at different instances, with latest generations of PCE based products before implementing the engineering changes.

Assessment will be conducted in natural clay-contaminated sand as well as in artificially doped sand with Sodium Montmorillonite Clay in both concrete and mortar. The aim of this assessment is to show and ascertain the improved performance of the newly formulated product, and to demonstrate its advantages in terms of water reduction capability, initial consistency and workability retention in clay-laden systems without adversely effecting concrete and mortar properties. 


\section{Experimental}

\subsection{Materials}

The cement used in all experiments is an ordinary Portland cement. For mortar trials, it was supplied by Holcim (CEM I 42.5R) (EN 197-1), and for concrete trials by Dubai cement (DXB). Characteristics of both cements are shown in Table 1. The particle size distribution of both cements was very similar as measured by laser diffraction, with an average particle size d50 of $18.0 \mu \mathrm{m}$ for the CEM I 42.5R and $17.4 \mu \mathrm{m}$ for the DXB cement.

Table 1. Phase composition (wt. \%) by QXRD and BET surface area of CEM I and DXB cements.

\begin{tabular}{|l|c|c|}
\hline Phase & CEM I & DXB \\
\hline Alite & 58.9 & 60.4 \\
\hline Belite & 14.4 & 12.8 \\
\hline Brownmillerite & 5.2 & 8.3 \\
\hline C3A_cubic & 5.9 & 1.8 \\
\hline C3A_ortho & 2.3 & 2.7 \\
\hline Lime & 0 & 0 \\
\hline Periclase & 0 & 0.2 \\
\hline Portlandite & 0.6 & 1 \\
\hline Calcite & 6.3 & 6.1 \\
\hline Gypsum & 0.6 & 0.4 \\
\hline
\end{tabular}

\begin{tabular}{l|c|c|}
\cline { 2 - 3 } \multicolumn{1}{c|}{} & CEM I & DXB \\
\hline Hemihydrate & 2.5 & 4.4 \\
\hline Anhydrite & 2.6 & 0.6 \\
\hline Arcanite & 0.4 & 0.8 \\
\hline Quartz & 0.1 & 0.2 \\
\hline Aphthitalite & 0.4 & 0.2 \\
\hline \multicolumn{2}{|c|}{} \\
\hline Total $\mathrm{SO}_{3}$ & 3.5 & 3.4 \\
\hline \multicolumn{2}{|c|}{} \\
\hline BET SA $\left(\mathrm{m}^{2} / \mathrm{g}\right)$ & 0.9360 & 1.1329 \\
\hline \multicolumn{2}{|c|}{} \\
\hline
\end{tabular}

The sand used in mortar tests is a CEN standard sand (EN 196-1), having naturally equant, rounded, clean and reasonably graded particles. Its lithology is mainly quartz. Table 2 and Figure 1 refer to the standard sand used.

Table 2. Sieve analysis of standard sand.

\begin{tabular}{|l|c|}
\hline Sieve & Retained \\
\hline $2.36 \mathrm{~mm}$ & $0.0 \%$ \\
\hline $1.18 \mathrm{~mm}$ & $27.6 \%$ \\
\hline $600 \mu \mathrm{m}$ & $35.4 \%$ \\
\hline $300 \mu \mathrm{m}$ & $8.7 \%$ \\
\hline $150 \mu \mathrm{m}$ & $20.4 \%$ \\
\hline $75 \mu \mathrm{m}$ & $7.8 \%$ \\
\hline $20 \mu \mathrm{m}$ & $0.1 \%$ \\
\hline
\end{tabular}

Fig. 1. Macro examination and petrographic thin section of standard sand. 
For concrete tests, the aggregates used were of the type gabbro and were collected from the Fujairah area in the United Arab Emirates.

In all trials where clay was intentionally introduced, it was dry sodium montmorillonite, a white fine powder with a minimum of $99 \%$ of the particles being finer than size $74 \mu \mathrm{m}$, having a surface area around $750 \mathrm{~m}^{2} / \mathrm{g}$ and a specific gravity of 2.6 . A typical elemental analysis would show the $\mathrm{SiO}_{2}$ content to be around $75 \%$ and the $\mathrm{Al}_{2} \mathrm{O}_{3}$ content to be around $15 \%$.

Two different types of superplasticizers, all being Polycarboxylate Ethers (PCE) were tested:

1. G type ADVA product, supplied by GCP Applied Technologies, and known for its robustness in concretes made with difficult sands. It will be referred to as AD1 in succeeding trials.

2. G type product based on CLARENA ${ }^{\circledR}$, specifically developed by GCP Applied Technologies for concrete mixes with high clay contents. It will show under the code AF2 and AF3 in succeeding trials depending on the application.

\subsection{Equipment and testing of engineered clay-tolerant solution}

\subsubsection{Determination of the clay content in sand}

The clay content of sand was measured using ASTM C1777-15, Standard Test Method for Rapid Determination of the Methylene Blue Value for Fine Aggregate or Mineral Filler Using a Colorimeter. The sand is dried at $105{ }^{\circ} \mathrm{C}$ to eliminate all the moisture and to a constant mass. After impregnation in methylene blue, the absorbance of the solution is measured at specific wave length and the methylene blue value is correlated to a corrected percentage of clay in the sand in form of sodium montmorillonite.

\subsubsection{Testing protocol in mortar}

The objective behind these experiments is to show the improved performance of $\mathrm{AF}$ samples in mortar at different intensities of clay doping, in relation to extended workability or dose efficiency. Below steps were followed for all experiments:

- Weigh water $(220 \mathrm{~g})$ in mixing bowl.

- Weigh clay in fine powder form directly in water.

- Mix manually in order to get uniform distribution of the powder.

- Start by mixing for one minute using a mixer with a blade rotating axially in a planetary motion at a speed of $60 \mathrm{rpm}$.

- Add the EN sand (1350 g) during the next 30 seconds, continue mixing for an additional minute and a half.

- Allow the mixture to rest for 2 minutes.

- Add $700 \mathrm{~g}$ of cement, mix manually, add superplasticizer dispersed in $20 \mathrm{~g}$ of water to the mixture, and mix manually up to 1 minute.

- Continue mixing for additional 4 minutes, always at the same speed.

In total, this mixing procedure takes 10 minutes.

Mortars were kept during preparation, mixing and testing at all times at a temperature of $24.0 \pm 2.0^{\circ} \mathrm{C}$.

The flow of the mortar is tested using a mini-slump cone, straight after mixing, 30 minutes and 60 minutes from the first flow. 
During the same time, the change in consistency and stiffening behaviour was monitored using a rotational viscometer, while ramping to 60 or $120 \mathrm{rpm}$ and in both directions over time. Figure 2 shows the profile being used for this study.

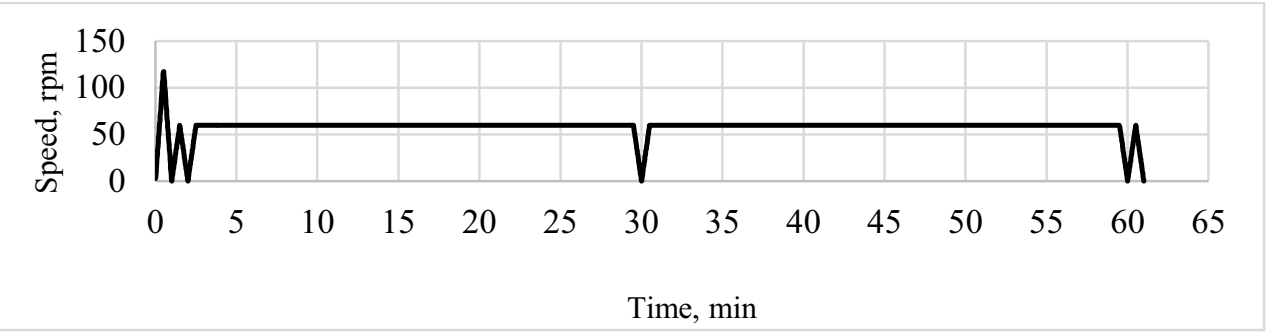

Fig. 2. Testing profile of the rotational viscometer over time.

\section{Results and discussion}

\subsection{Screening of different sands for clay content}

Many sands, natural and manufactured, washed and unwashed, were collected from different parts of the Arabian Gulf region and were tested for clay. The purpose was a better understanding of the levels of contamination we may encounter. Different levels of clay contamination were detected, depending on the location of the mining site, geology, washing and sieving processes and their efficiency. Figure 3 shows the distribution of sodium montmorillonite equivalent content for 21 samples. $14 \%$ of the samples can be classified as relatively clean, with sodium montmorillonite equivalent contents below $0.5 \%$ and little detrimental effects especially on plastic properties of concrete. $29 \%$ of the samples are moderately contaminated with sodium montmorillonite equivalent contents between $0.5 \%$ and $1.0 \%$, while $57 \%$ are heavily contaminated above $1.0 \%$ with severe effects on the concrete properties in the plastic stage, hidden costs implications and limitations on mix designs, performance parameters and targeted applications.

These figures are highly indicative of the importance of any solution dealing with these materials and the accompanying positive impact on the construction industry.

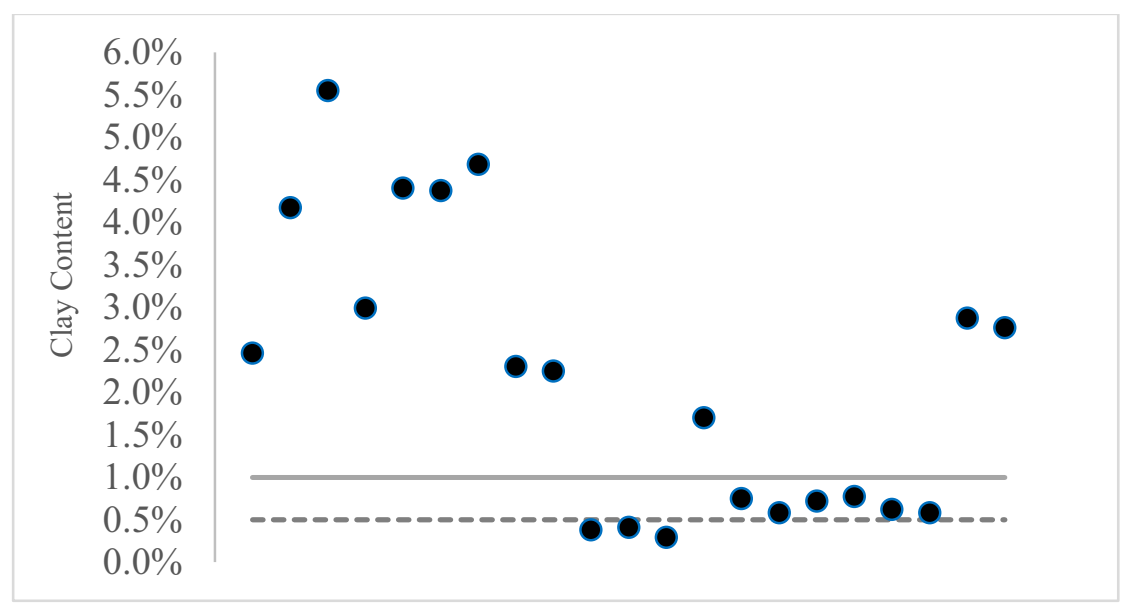

Fig. 3. Levels of corresponding clay contamination in 21 sand samples. 


\subsection{Mortar tests while doping sand with $0.20 \%$ sodium montmorillonite}

The first tests were done with $2.73 \mathrm{~g}$ of sodium montmorillonite, corresponding to clay content of $0.20 \%$ by weight of sand. The mixture consisted of $240 \mathrm{~g}$ of water, $1350 \mathrm{~g}$ of EN sand and $700 \mathrm{~g}$ of CEM I $42.5 \mathrm{R}$ cement. Table 3 represents the results of mini-slump flow obtained measured according to ASTM C1437-15. The dosages mentioned in the same table are \% solids/solids corresponding to the dry solids content of the PCE material per cement content in mortar.

Table 3. Flow measured according to ASTM C1437 in mortar tests with $0.20 \%$ Sodium Montmorillonite.

\begin{tabular}{|l|c|c|c|}
\hline Experiment & E1 & E2 & E3 \\
\hline Additive & AD1 & AF2 & AD1 \\
\hline Dosage, \% s/s & $0.186 \%$ & $0.186 \%$ & $0.186 \%$ \\
\hline Flow, Initial, mm & 220 & 230 & 220 \\
\hline Flow, 30 $\mathbf{~ m i n , ~ m m ~}$ & 195 & 200 & 190 \\
\hline Flow, 60 $\mathbf{~ m i n , ~ m m ~}$ & 160 & 160 & 150 \\
\hline
\end{tabular}

These tests were planned for commencement aiming to get a baseline or starting point for the rest of our evaluation study and comparisons. Experiments E1 and E2 are very clear in indicating the similar performance of $\mathrm{AD} 1$ and $\mathrm{AF} 2$ at same dosage rate in clean to slightly clay contaminated sand. When sodium montmorillonite was added at a low amount, both AD1 and AF2 exhibit the same water reduction characteristics in terms of initial consistency and workability retention in mortar.

Experiment E3 was a repeat of E1 to check the variability of the test - it can be seen that the testing protocol is well controlled with minimum variability in all involved measurements.

\subsection{Mortar tests while doping sand with $0.60 \%$ sodium montmorillonite}

In these trials $8.1 \mathrm{~g}$ of sodium montmorillonite were added to the sand, corresponding to $0.60 \%$ by weight of sand. The mixture consisted of $240 \mathrm{~g}$ of water, $1350 \mathrm{~g}$ of EN sand and $700 \mathrm{~g}$ of CEM I $42.5 \mathrm{R}$ cement. Table 3 represents the results of mini-slump flow obtained. The dosages mentioned in the same table are \% solids/solids corresponding to the dry solids of PCE material per cement content in mortar.

Table 4. Flow measured according to ASTM C1437 in mortar tests with $0.60 \%$ Sodium Montmorillonite..

\begin{tabular}{|lc|c|c|c|c|c|}
\hline Experiment & X1 & X2 & X3 & X4 & X5 & X6 \\
\hline Additive & AD1 & AF2 & AF2 & AD1 & AF2 & AF2 \\
\hline Dosage, \% s/s & 0.345 & 0.345 & 0.328 & 0.345 & 0.335 & 0.331 \\
\hline Flow, Initial, mm & 210 & 250 & 185 & 200 & 230 & 210 \\
\hline Flow, 30 min, mm & 170 & 225 & 155 & 170 & 200 & 180 \\
\hline Flow, 60 min, mm & 155 & 190 & 140 & 155 & 170 & 145 \\
\hline
\end{tabular}

Looking at Table 4, one can immediately notice the considerably enhanced initial flow and extended flow retention of the additive AF2 when compared to AD1 at the same dosage in experiments $X 1$ and $X 2$. We are able to reduce the dosage of AF2 by more than $4 \%$, 
keeping at all times a flow within a range $\pm 10 \mathrm{~mm}$ when compared to AD1, when examining experiments X5 and X6.

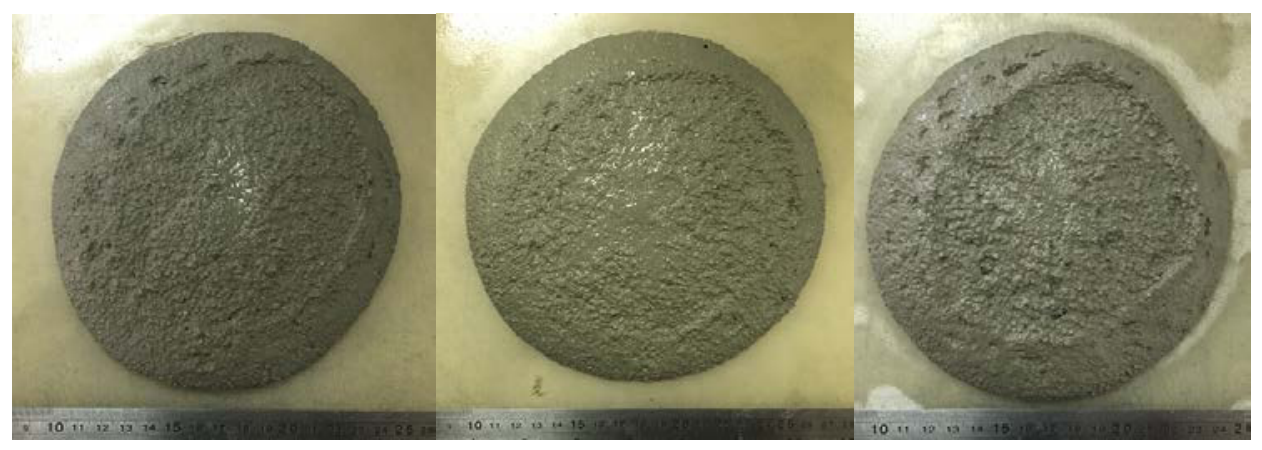

Fig. 4. Flow test of mortar after 60 minutes in experiments $\mathrm{X} 4, \mathrm{X} 5$ \& $\mathrm{X} 6$ (from left to right)

Experiments $\mathrm{X} 1$ and $\mathrm{X} 4$ show again good repeatability of the test results.

Another way to understand the workability of above mixtures is by using a rotational viscometer (Viskomat NT) and record variations in torque as a function of time or stirring speed $[19,20]$. Such measures were conducted for 4 mixes as shown in Figure 4. A higher torque value indicates a mortar mix with lower workability.

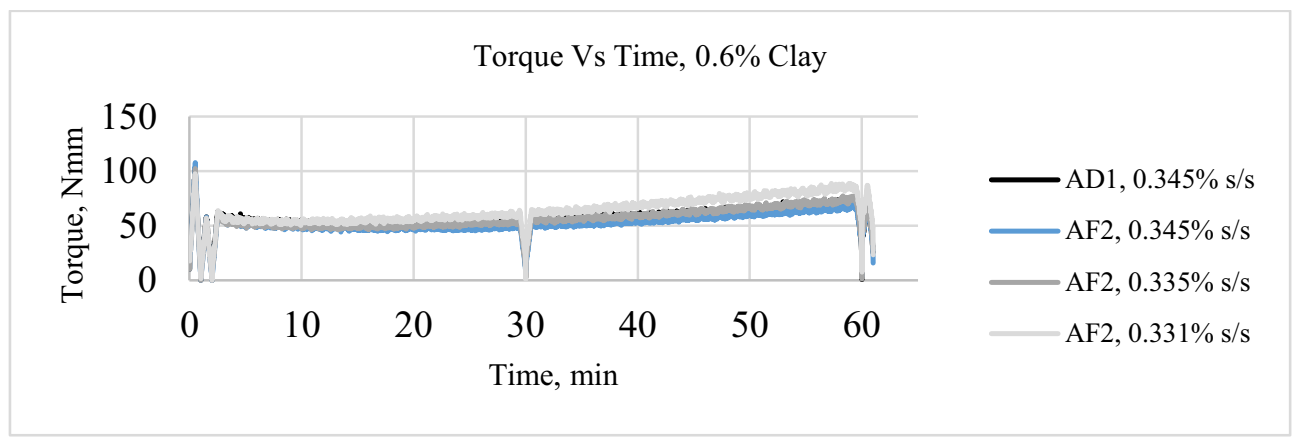

Fig. 5. Representation of the torque in relation to time of the mortar in a rotational viscometer.

The torque versus time curves presented in Figure 5 indicate that all the 4 mixes followed almost the same stiffening behavior over time, with AD1 at $0.345 \% \mathrm{~s} / \mathrm{s}$ and AF2 at a reduced dosage rate of $0.335 \% \mathrm{~s} / \mathrm{s}$ perfectly matching. Both are bound by AF2 at $0.345 \% \mathrm{~s} / \mathrm{s}$ from below with more fluid consistency and higher workability, and AF2 at $0.331 \% \mathrm{~s} / \mathrm{s}$ from top with slightly lower workability.

In the aim of having a closer look to the behavior of two similar mixtures with AD1 at $0.345 \% \mathrm{~s} / \mathrm{s}$ and AF2 at reduced dosage $0.335 \% \mathrm{~s} / \mathrm{s}$, Figure 6 illustrates the torque in relation to the speed measured using Viskomat NT while ramping down from $60 \mathrm{rpm}$ to $0 \mathrm{rpm}$ after 60 minutes from mixing. 


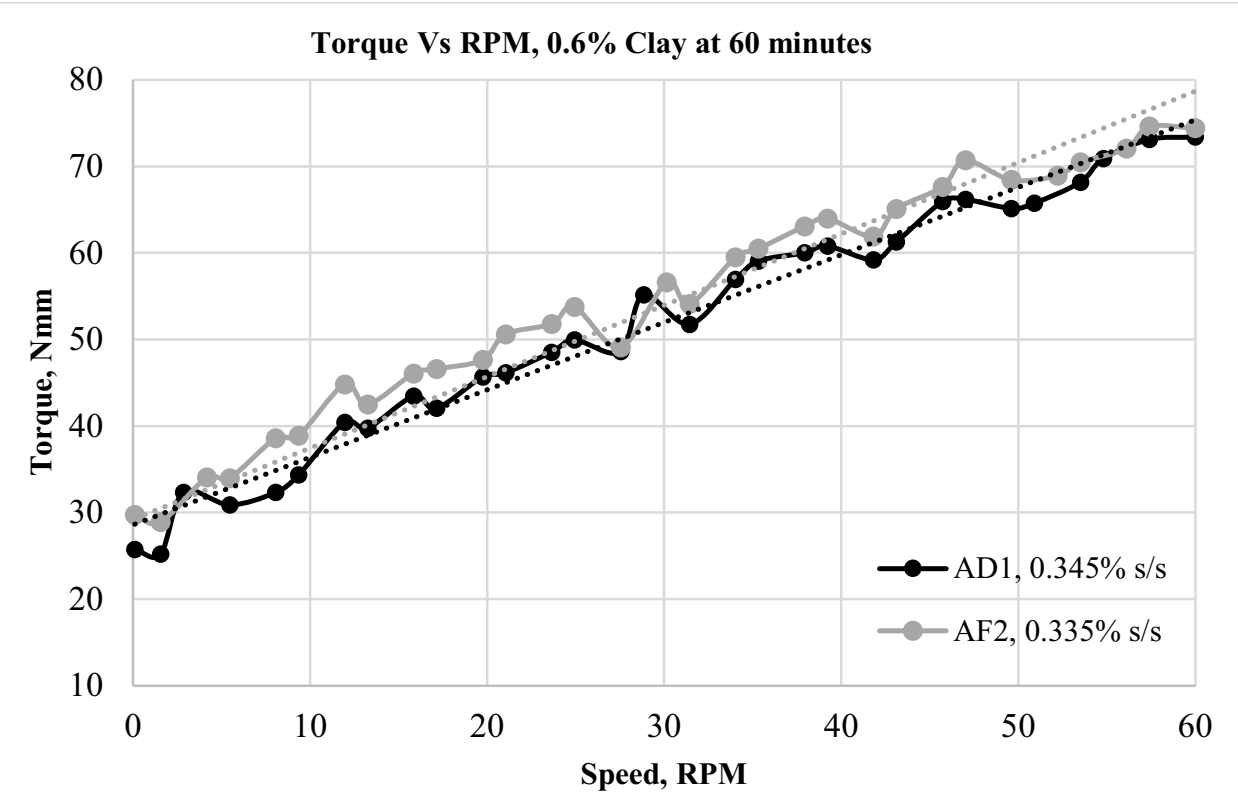

Fig. 6. Representation of the torque in relation to the rotational speed in a rotational viscometer

As a first order approximation, a linear relationship for both curves with respective equations displayed below is suggested:

$$
\begin{aligned}
& \mathrm{AD} 1 \text { at } 0.345 \% \mathrm{~s} / \mathrm{s}: y=0.780 x+28.6 ; R^{2}=0.978 \\
& \mathrm{AF} 2 \text { at } 0.335 \% \mathrm{~s} / \mathrm{s}: y=0.825 x+29.2 ; R^{2}=0.960
\end{aligned}
$$

The 2 curves are closely matching and the intercepts are almost equal.

Seeing that the 2 curves follow the model relation shear stress / shear rate, we can propose that the intercepts are proportional to the yield points of the 2 mixtures [20,21], and in this case being approximately identical.

To attain similar workability and rheology of mortar with $0.60 \%$ sodium montmorillonite, $\mathrm{AF} 2$ at almost $3 \%$ reduced dosage is equivalent to $\mathrm{AD} 1$.

\subsection{Mortar tests while doping sand with $\mathbf{0 . 8 0 \%}$ sodium montmorillonite}

Another set of tests was designed by increasing the amount of sodium montmorillonite to $10.8 \mathrm{~g}$, corresponding to $0.80 \%$ by weight of sand. The mixture consisted of $240 \mathrm{~g}$ of water, $1350 \mathrm{~g}$ of EN sand and $700 \mathrm{~g}$ of CEM I $42.5 \mathrm{R}$ cement. Table 5 represents the results of the mini-slump flow obtained. The dosages mentioned in the same table are \% solids/solids corresponding to the dry solids PCE material per cement content in mortar.

The flow measures of experiments $\mathrm{P} 1$ and $\mathrm{P} 2$ in Table 5 demonstrates the improved performance of AF2 when compared to $\mathrm{AD} 1$ at same dosage, in what concerns plastic properties up to 60 minutes. In experiment P3 the flow measures with AF2, at a dosage reduction reaching $3 \%$, matched closely those with $\mathrm{AD} 1$ in $\mathrm{P} 1$. 
Table 5. Flow measured according to ASTM C1437 in mortar tests with $0.80 \%$ Sodium Montmorillonite.

\begin{tabular}{|l|c|c|c|}
\hline Experiment & P1 & P2 & P3 \\
\hline Additive & AD1 & AF2 & AF2 \\
\hline Dosage, \% s/s & $0.420 \%$ & $0.420 \%$ & $0.407 \%$ \\
\hline Flow, Initial, mm & 205 & 240 & 195 \\
\hline Flow, 30 min, mm & 170 & 200 & 160 \\
\hline Flow, 60 min, mm & 150 & 180 & 140 \\
\hline
\end{tabular}

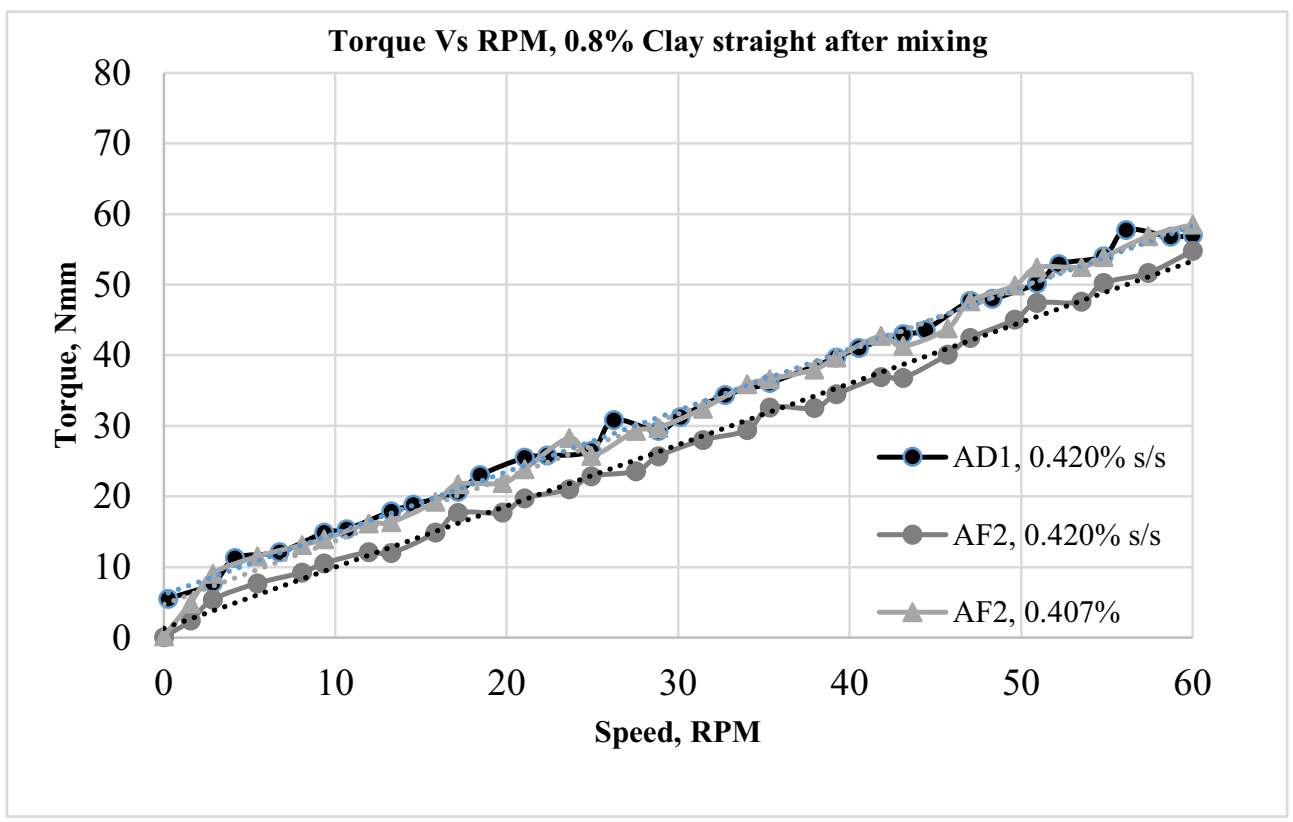

Fig. 7. Representation of the torque in relation to the rotational speed in a rotational viscometer.

Figure 7 represents the data collected from rotational viscometer straight after preparing the mortars in experiments $\mathrm{P} 1, \mathrm{P} 2$ and $\mathrm{P} 3$, in form of torque in relation to speed while ramping down from $60 \mathrm{rpm}$ to $0 \mathrm{rpm}$.

In Figure 7, the data points related to AD1 at $0.42 \% \mathrm{~s} / \mathrm{s}$ dosage and AF2 at $0.407 \% \mathrm{~s} / \mathrm{s}$ are scattered in such a way that their representative curves are almost extending over each other.

The data points of AF2 at $0.42 \% \mathrm{~s} / \mathrm{s}$ dosage are located lower than the other two curves, recording lower values of torque at every speed between 0 and $60 \mathrm{rpm}$.

A linear relationship for all the 3 data sets is proposed:

$$
\begin{aligned}
& \mathrm{AD} 1 \text { at } 0.420 \% \mathrm{~s} / \mathrm{s}, y=0.870 x+6.1 ; R^{2}=0.996 \\
& \mathrm{AF} 2 \text { at } 0.407 \% \mathrm{~s} / \mathrm{s}, y=0.899 x+4.7 ; R^{2}=0.993 \\
& \mathrm{AF} 2 \text { at } 0.420 \% \mathrm{~s} / \mathrm{s}, y=0.867 x+1.3 ; R^{2}=0.995
\end{aligned}
$$

Examining all the above data and the similarity in yield points, we can deduce the equivalency in performance between $\mathrm{AD} 1$ at $0.42 \% \mathrm{~s} / \mathrm{s}$ dosage and $\mathrm{AF} 2$ at a reduced dosage of $0.407 \% \mathrm{~s} / \mathrm{s}$. Mortar with AF2 at a higher dosage of $0.42 \%$ remains more fluid. 
This is a case for a moderate sand contamination, where we witness the value of an emerging technology having a potential in solving technical problems related to cement mixtures consistency and slump retention with difficult clay contaminated sand.

\subsection{Mortar tests while doping sand with $1.20 \%$ sodium montmorillonite}

The last set of mortar trials was done by increasing the amount of sodium montmorillonite further to $16.2 \mathrm{~g}$, corresponding to $1.20 \%$ by weight of sand. The mixture consisted of 240 $\mathrm{g}$ of water, $1350 \mathrm{~g}$ of EN sand and $700 \mathrm{~g}$ of CEM I $42.5 \mathrm{R}$ cement. Table 6 represents the results of mini-slump flow obtained. The dosages mentioned in the same table are \% solids/solids corresponding to the dry solids PCE materials per cement content in mortar.

Table 6. Flow measured according to ASTM C1437 in mortar tests with $1.20 \%$ Sodium Montmorillonite.

\begin{tabular}{|l|c|c|c|c|c|}
\hline Experiment & R1 & R2 & R3 & R4 & R5 \\
\hline Additive & AD1 & AF2 & AF2 & AF2 & AF2 \\
\hline grams & 9.03 & 9.03 & 8.58 & 8.4 & 8.22 \\
\hline Dosage, \% s/s & $0.645 \%$ & $0.645 \%$ & $0.613 \%$ & $0.600 \%$ & $0.587 \%$ \\
\hline Flow, Initial, mm & 190 & 260 & 220 & 210 & 195 \\
\hline Flow, 30 min, mm & 170 & 250 & 205 & 195 & 160 \\
\hline Flow, 60 $\mathbf{~ m i n , ~ m m ~}$ & 160 & 235 & 180 & 180 & 150 \\
\hline
\end{tabular}

At high levels of clay contamination the improved performance of AF2 when compared to $\mathrm{AD} 1$ at the same dosage rate can be clearly seen, with respect to plastic properties of mortars in experiments R1 and R2 up to 60 minutes.

To have a better understanding of the rheology of the two mixtures in experiments R1 and R5, Viskomat NT, a rotational viscometer, was used and the variation of the torque in relation to the rotational speed was measured during a ramp down from $60 \mathrm{rpm}$ to $0 \mathrm{rpm}$.

Figure 8 shows the two curves related to AD1 at $0.645 \% \mathrm{~s} / \mathrm{s}$ dosage and AF 2 at $0.587 \% \mathrm{~s} / \mathrm{s}$ closely matching from 60 to $0 \mathrm{rpm}$. The torque of AF2 at $0.645 \% \mathrm{~s} / \mathrm{s}$ dosage rate is lower than the other two curves from 60 to $0 \mathrm{rpm}$. In fact, this was seen in experiment R2 where the flow values recorded were higher and the mixture looked much more fluid.

The linear correlations for the two experiments R1 and R5 are mentioned as follows:

$$
\begin{aligned}
& \mathrm{AD} 1 \text { at } 0.645 \% \mathrm{~s} / \mathrm{s}, y=0.990 x+5.8 ; R^{2}=0.991 \\
& \mathrm{AF} 2 \text { at } 0.587 \% \mathrm{~s} / \mathrm{s}, y=1.078 x+5.8 ; R^{2}=0.992
\end{aligned}
$$

All above data and the full agreement between the flow measured according to ASTM $\mathrm{C} 1437$ and the yield points determined from experiments R1 and R5 are a key performance indicator translated in dose reduction close to $9 \%$, while AF2 is keeping a steady efficiency comparable to $\mathrm{AD} 1$ within a flow range $\pm 10 \mathrm{~mm}$ extended over one hour of time. 


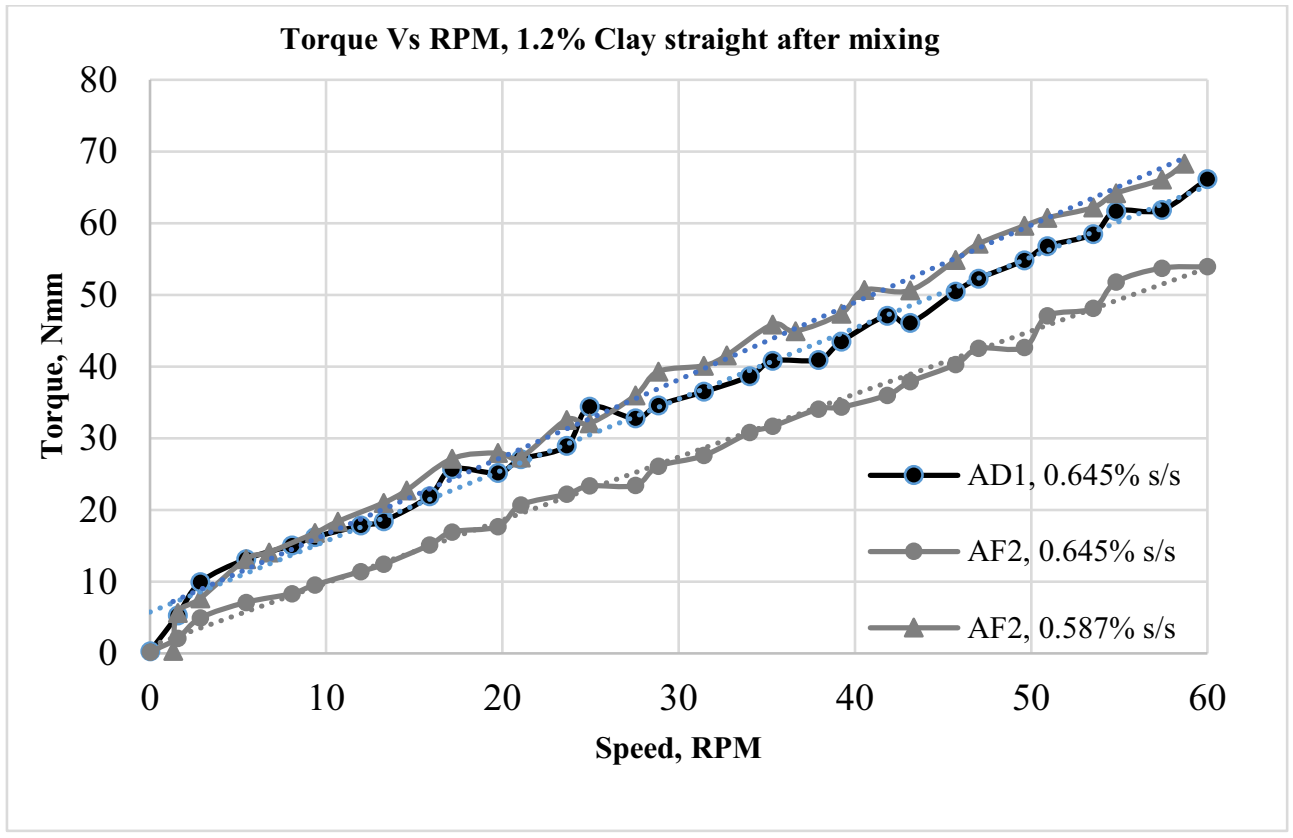

Fig. 8. Representation of the torque in relation to the rotational speed in a rotational viscometer.

At high sand contamination, the added value of the CLARENA ${ }^{\circledR}$ is clear and obvious in terms of improved plastic properties of cement mixtures or reduction of the required dose of dispersants to meet consistency parameters.

In the following section, the influence of coarse aggregates on the workability and flowability of concrete will be investigated.

\subsection{Field case}

This technology was applied in a practical difficult case in the field to validate the findings from the laboratory. It was a K650 concrete using $480 \mathrm{~kg}$ of OPC and $40 \mathrm{~kg}$ of silica fume at a low water to cement ratio equal to 0.28 . Many different dispersants based on various technologies available in the market were tried at high dosages exceeding $10 \mathrm{~kg} / \mathrm{m}^{3}$, and the common performance characteristic was a quick loss of workability bringing the flow from around $600 \mathrm{~mm}$ flow to an almost zero slump concrete after 30 minutes from mixing. It was speculated that the poor performance was most likely linked to the clay contaminants in the sand. This triggered the idea to try AF3 in the same concrete mixture and check the capability of the new admixture.

Table 7. Measures of improved slump flow in K650 concrete

\begin{tabular}{|c|c|c|c|c|}
\hline Additive & Dosage, $\mathbf{~ k g} / \mathbf{m}^{\mathbf{3}}$ & Initial Flow, $\mathbf{m m}$ & Flow, 30 min & Flow, 60 min \\
\hline AF3 & 9.5 & 670 & 530 & 400 \\
\hline
\end{tabular}

Table 7 shows the possibility of applying this technical solution for situations, where the problems reside in maintaining a workable concrete for a certain period of time and being pumpable. Such situations are frequently seen with higher grades concrete, where the clay content in the sand used is beyond a critical value. 


\section{Conclusions}

The aim of the current study is to introduce and prove the efficiency of a newly engineered class of dispersants, providing a solution for workability complications, primarily concerning concrete properties in the plastic and hardened stage and specifically accompanying with the use of clay contaminated sand. This new family of products based on redesigned polymers, demonstrated an improvement in performance, with a pronounced flexibility in adjusting the initial fluidity, consistency and workability retention of concrete, a possibility of reducing the required dosage rates, as well as reducing water to cement ratios. In some difficult cases, the use of these products is imperative to overcome high clay contents in sand and to meet required technical parameters. All the preceding positive facts were assessed in mortar tests at different sodium montmorillonite doping degrees equivalent to $0.2 \%, 0.6 \%, 0.8 \%$ and $1.2 \%$ by weight of sand. Measures of slump flow and flow curves using a rotational viscometer, demonstrated the considerably improved workability of the tested solution AF at same dosages as the reference product AD. Finally, in extreme real conditions of steep loss of workability due to clay content exceeding some defined limits, CLARENA ${ }^{\circledR}$ confirmed to be the right key solution in extending slump life and providing pumpable concrete. Our proposed solution must be presented as a sustainable answer to the rigorous sand washing process practiced currently. It can help in modifying and shortening the phases of this process with all the concomitant benefits like preserving water, avoiding costs and reducing wastes. In addition, it is important to mention the beneficial roles that clay and fines can play if kept in concrete such as reduction in bleeding, segregation and formwork lateral pressure.

In future, it is a must to understand better the mode of action of these new polymers, their adsorption plus their dispersive and sacrificial effect on clay in restoring the anticipated dose-response of PCEs. Also continuous screening of sand and validation of the technology in different geographical locations is needed to broaden the scope of applications.

\section{References}

1. M. Al-Ansary, M. C. Poppelreiter, A. Al-Jabry, S. R. Iyengar, International Journal of Sustainable Built Environment 1, 64-84 (2012)

2. C. M. Ouellet-Plamondon, G. Habert, Journal of Cleaner Production 117, 160-168 (2016)

3. L. Lei, J. Plank, Cement and Concrete Research 42, 1299-1306 (2102)

4. M.L. Nehdi, Construction and Building Materials 51, 372-382 (2014)

5. Long xiong, Guangjun Zheng, Yao Bi, Chengfei Fu, Effect of typical clay upon the dispersion performance of polycarboxylate superplasticizer. International Conference on Materials, Environmental and Biological Engineering, (MEBE 2015)

6. N. A. Tregger, M. E. Pakula, S. P. Shah, Cement and Concrete Research 40, 384-391 (2010)

7. M. Heikal, N.S. Ibrahim, Construction and Building Materials 112, 19-27 (2016) 
8. J. K. Norvell, J. G. Stewart, M. C. G. Juenger, and D. W. Fowler, Journal of Materials in Civil Engineering C ASCE / December / 1053 (2007)

9. A. A. Jeknavorian, L. Jardine, C. C. Ou, H. Koyata, and K. Folliard, Seventh CANMET/ACI International Conference SP-217, 1293-1316, (2003)

10. L. M. Olanitori. Mitigating the Effect of Clay Content of Sand on Concrete Strength. 31st Conference on OUR WORLD IN CONCRETE \& STRUCTURES

11. H. AlShemmari, A. M. Al-Dousari, L. Talebi, A. N. Al-Ghadban, Kuwait J. Sci. 40 (2), 159-176 (2013)

12. Elhabab and Adsani, Geochemical and Mineralogical Characters of the Coastal Plain Sediments of the Arabian Gulf, Kuwait. J Geol Geosci 3:1 (2013)

13. MURAD D. A. Environmental Impact Assessment Case Study of the Quarries in Kuwait. Environmental Planning and Impact Assessment Department, Environment Public Authority, Kuwait.

14. T. Hirata, Japanese Patent JP 84, 2022 (S59-018338) (1981)

15. Flatt, R., Schober, I., Superplasticizers and the rheology of concrete. In: Roussel, N. (Ed.), Understanding the Rheology of Concrete. Woodhead Publishing, Cambridge, UK, 144-208 (2012)

16. H. Uchikawa, S. Hanehara, D. Sawaki, Cem. Concr. Res. 27, 37-50 (1997)

17. C.Z. Li, N.Q. Feng, Y.D. Li, R.J. Chen, Cem. Concr. Res. 35, 867-873 (2005)

18. Ouellet-Plamondon, C.M., Stasiak, J., Al-Tabbaa, A., Colloids Surf. A: Physicochem. Eng. Asp. 444, 330-337 (2014)

19. Al-Ghadban, A. and A. El-Sammak, Sources, Journal of Arid Environments, 60, 647$661(2005)$

20. P. F. G. Banfill, Magazine of Concrete Research, 43 (154), 13-2 (1991)

21. Robert J. Flatt, Domenico Larosa, Nicolas Roussel, Cement and Concrete Research 36, 99 - 109 (2006)

22. P. F. G. Banfill, Magazine of Concrete Research, 42 (153), 213-221 (1990)

23. R.M. Quigley, F.J. Heffernan, Engineering Geology 2 (5), 351-356 (1968) 